\title{
Improvement in Knowledge, Attitude and Practice of Iron Deficiency Anaemia among Iron-Deficient Female Adolescents after Nutritional Educational Intervention
}

\author{
Marwan O. Jalambo ${ }^{1}$, Razinah Sharif ${ }^{1}$, Ihab A. Naser ${ }^{2}$ \& Norimah A. Karim ${ }^{1}$ \\ ${ }^{1}$ Faculty of Health Sciences, University Kebangsaan Malaysia (UKM), Malaysia \\ ${ }^{2}$ Department of clinical Nutrition, Faculty of Applied Medical Science, Al-Azhar University, Gaza \\ Corresponding: Norimah A. Karim, Nutrition Science Programme, Faculty of Health Sciences, UKM, Jalan Raja \\ Muda Abdul Aziz, 50300 Kuala Lumpur, Malaysia. Tel: 603-9289-7622. E-mail: norimahkarim@ukm.edu.my
}

Received: December 5, 2016 Accepted: December 28, 2016 Online Published: January 3, 2017

doi:10.5539/gjhs.v9n7p15

URL: http://dx.doi.org/10.5539/gjhs.v9n7p15

\begin{abstract}
Anaemia and iron deficiency are very common worldwide among female adolescents. There is a dearth of literature concerning the knowledge, attitude and practice (KAP) regarding iron deficiency anaemia (IDA). The magnitude of anaemia as a health problem is enormous and can be engaged by increasing awareness and the promotion of correct attitudes and practices. The study aims to evaluate the effectiveness of a nutrition education intervention in iron deficiency anaemia on the knowledge, attitude, and practice (KAP) among iron-deficient female adolescents in the Gaza Strip. In this intervention study, 89 female adolescents aged 15-19 were recruited and randomly divided into intervention and control groups. Both of the groups received iron supplementation (ferrous fumarate $200 \mathrm{mg}$ ) weekly for three months. The intervention group attended nutrition education sessions for 3 months, while the control group did not. The two groups completed KAP questionnaires at baseline and after six months. The nutrition education intervention consisted of lectures, presentations, interactive discussions using posters, and the distribution of information booklets and brochures about proper nutrition, and was conducted for three months. KAP and overall scores before and after the intervention were compared using the Wilcoxon signed ranks test, as the scores did not show normal distribution. Our findings revealed that overall, the female adolescents' knowledge improved significantly after a nutrition education intervention, as the percentage of good knowledge ( $\geq 50 \%$ ) was $22.7 \%$ pre-nutrition educational intervention, and increased to $90.9 \%$ post intervention ( $p$ $<0.001)$ in the intervention group. Attitude and practice also improved from $36.4 \%$ and $54.5 \%$ at pre-test to $75.5 \%$ and $75.5 \%(p<0.001$ and $p<0.002)$ at post-test, respectively. Nutrition education intervention has an impact on improving knowledge, attitude and practices of iron-deficient female adolescents compared with control. The nutrition programme should be adopted and integrated into comprehensive intervention programmes to target IDA among adolescents at various levels in Palestine.
\end{abstract}

Keywords: nutrition, knowledge, attitude, practice, adolescents, Palestine

\section{Introduction}

Several studies report a lack of appropriate knowledge and attitude regarding healthy eating among adolescents and consequent unhealthy eating behaviour (Divakaran, Muttapillymyalil, Sreedharan, \& Shalini, 2010; Puri, Bhatia, Swami, Rai, \& Mangat, 2008; WHO, 2010). A desire to consume a healthy and balanced food may exist, but it does not translate fully to behaviour modification. Continuous eating of unhealthy food leads to serious health problems (Elhassan, Gamal, \& Mohammed, 2013). Achieving the desired changes of behaviour in health and nutrition depends on gaining sufficient knowledge, attitudes, good practice, and self-efficacy (Shariff Mohd Zalilah et al., 2008). Nutrition education is the type of intervention that aims to address malnutrition by initiating behavioural change. The majority of adolescents can be reached effectively through schools, which is an appropriate place for health education (Øvrebø, 2014). Moreover, nutritional education includes gaining of knowledge and behaviour changes regarding food consumption and nutrition-related practices (Nguyen et al., 2013).

Nutrition knowledge is essential for individuals to acquire a lifestyle that is healthy and free from disease (Roszanadia \& Norazmir, 2011). A study carried out in Malaysia indicates that the knowledge, attitude, and 
practice of undergraduate students on healthy eating improved after intervention (Aung, Foung, Azman, Ain, \& Zulkifeli, 2012). Improving the nutrition attitudes, knowledge, and practices of adolescents and youth is very important as it will lead to a more food-conscious society and healthier individuals (Elhassan et al., 2013). Another study conducted in Malaysia reported that a comprehensive and progressive nutritional education is required to provide schoolchildren with the knowledge and skills for acquiring healthy nutrition-related behaviours (Shariff Mohd Zalilah et al., 2008).

A recent study in the USA revealed the importance of behavioural studies which applied to adolescent survival programming (Waisbord, 2014). The three components to demonstrate the behaviours are knowledge, attitude, and practice (KAP) (Black et al., 2013). These determinants in the community become the main factors to encourage the occurrence of nutrition and health problems. Studies on community determinants on such balanced diet behaviour (knowledge, attitude, and practice balanced diet) in relation to microcytic hypochromic anaemia are still very limited (Patimah, Royani, Mursaha, \& Thaha, 2016). A recent 2015 study conducted in India reported that nutrition education intervention was essential for female adolescents to create awareness of and to disseminate knowledge related to the control and prevention of anaemia (Priyanka \& Asfia, 2015).

KAP assessment is suitable to evaluate the effectiveness of intervention programs. Moreover, it can assess a target group's current knowledge, attitude, and practice regarding a specific topic to detect their needs, problems, and possible barriers before developing and implementing the intervention study (Hiew, Chin, Chan, \& Mohd, 2015; WHO, 2008). It identifies what the study sample already knows (Knowledge), how they feel (Attitude), and what they do (Practice) (Vandamme, 2009). In recent studies on nutrition, knowledge, attitude, and practice evaluation has been commonly used (Hiew et al., 2015). KAP was used to evaluate the knowledge on the management of iron deficiency anaemia among adolescent female in European countries (Sichert-Hellert et al., 2011).

To the best of our knowledge, there is no published knowledge assessment questionnaire for evaluating iron deficiency or anaemia that had been developed in or for use in the Gaza Strip, Palestine. This study used a recent KAP questionnaire derived from FAO to use as an evaluation tool of KAP among adolescents (FAO, 2014). Furthermore, questions on attitude and practice related to IDA were used to identify the level of right attitude and practice towards health (Marías \& Glasauer, 2014). There is very limited published information on the impact of nutrition education among adolescents in Palestine. In this study, we conducted a nutrition education intervention to improve knowledge, attitude, and practice among iron-deficient female adolescents in the Gaza Strip, Palestine. The current study aimed to assess the effectiveness of nutritional education levels, based on the improvement of knowledge, attitude, and practice.

\section{Methodology}

Phase one of the study was a cross-sectional study and the second was a randomised control trial. This study was carried out in five female secondary schools randomly selected from the Gaza Strip, Palestine, from September 2015 to April 2016. One secondary school was chosen in each of the five governorates in the Gaza Strip. Female adolescents aged 15-19 years were selected on a voluntary basis after obtaining informed consent. Serum ferritin, complete blood count, erythrocytes sedimentation rate, and C-reactive protein were measured. All female adolescents who were diagnosed iron deficient (serum ferritin $<15 \mu \mathrm{g} / \mathrm{l}$ ) in phase one were enrolled in the randomised control trial study in phase two. A total of 89 iron deficient and iron deficient anaemic female adolescents were recruited from the screening phase. The recruited subjects were divided into two parallel groups: a control group and a nutritional education (intervention) group. Data from the questionnaires were collected through group interviews with adolescents in each of the two groups. Both groups received iron supplements (ferrous fumarate $200 \mathrm{mg}$ ) weekly for three months. An educational intervention using lectures, presentations, interactive discussions, posters, and the distribution of information booklets and brochures about good nutrition was conducted among the intervention group, while the control group received the booklets and brochure only after the post-test KAP questionnaire was completed. KAP and overall scores before and after the intervention were compared using the Wilcoxon signed ranks test as the scores did not show a normal distribution.

\subsection{Sample Size Calculation}

A power calculation was carried out for the study which indicated that at least 80 female adolescents (40 in the control group and 40 in the intervention group) are required in each group (90\% power) to detect a significant difference $(\mathrm{p}<0.05)$ in KAP between the two groups. The final sample of the current study consisted of 89 female adolescents divided into two groups ( $\mathrm{n}=45$ for Control; $\mathrm{n}=44$ for Intervention).

\subsection{KAP Questionnaire Validity and Reliability}

Face validity aims to determine the adolescent's opinion on the suitability of the questionnaire questions (Miller $\&$ 
Lovler, 2015). First, the KAP questionnaire was professionally translated from English to the Arabic language. The translated version was then reviewed and thereafter translated back to English by a different translator, and the translation was refined during a refinement process. Thereafter, KAP questionnaires were distributed to the female adolescents. The female adolescents were asked to complete the KAP questionnaire and were encouraged to ask for clarification if needed. After experts determined the content validity, the KAP of iron deficiency anaemia was pre-tested among 35 female adolescents in remedial class to determine its face validity. The feedbacks from the pre-test were integrated to the KAP questionnaire before the start of fieldwork. These items were explained in a more understandable way and highlighted to be adjusted later. Test-retest reliability was done to determine the stability of a tool in different situations and over a period of time (Reynolds \& Livingston, 2013). A group of female adolescents from remedial classes $(n=35)$ were randomly selected to complete the same KAP questionnaire two weeks after the first administration of the KAP questionnaire to determine the test-retest reliability of the KAP questionnaire.

\subsection{Nutrition Education}

The purpose of the nutrition education was to teach the adolescents the importance of proper nutrition with an emphasis on iron deficiency and IDA. The nutrition education intervention group received nutrition education sessions during three months of intervention. They received nine sessions (one and half hour/session) during a three-month period of intervention. The intervention consisted of lectures, wall writings, video, booklets, and brochures. During the nutritional lectures, the researchers taught nutrition topics in simple, easily understood terms covering topics such as food groups, the food pyramid, balanced food, iron absorption enhancers and inhibitors, good sources of iron, and ways to improve absorption of iron from foods. The intervention programme also included basic concepts on how to obtain a balanced diet, anaemia in general and iron deficiency as a serious public health problem, growth and development according to what we eat, and iron-rich sources of the foods. At the end of the intervention, the same KAP questionnaire was administered.

\subsection{KAP Questionnaire}

The nutrition education intervention in the current study was initiated with a nutrition KAP questionnaire to explore the previous nutrition KAP of the adolescents enrolled in the RCT study. KAP data was used to assess the KAP towards iron deficiency anaemia. The KAP questionnaire established what the adolescents knew about IDA symptoms, ability to diagnose, intervention necessity, and risk behaviour. In addition, KAP data demonstrated how people feel towards IDA, whether they are willing to protect themselves against IDA, and also established participants' awareness of the danger of IDA. The practice questions section in the KAP questionnaire gives an idea on how they protect themselves against IDA and whether the study sample engages in any risky behaviour.

\subsection{Scoring of KAP Questionnaire}

The researchers developed a scoring for each section of the questionnaire. KAP proficiency was tested with 17 multiple-choice questions. The questionnaire consisted of three parts comprising knowledge ( 8 questions), attitude (6 questions), and practice (3 questions). Answers to the knowledge part were either "known" or "do not know". Part one in the KAP questionnaire contained eight questions related to knowledge. The answers to each question were preliminarily classified as "know" or "do not know"; then, the answers were calculated and changed to a percentage in which four "do not know" answers equalled 50\%. In other words, participants whose answers were "do not know" for less than four questions were classified as having low knowledge, while those whose answers were "known" for four questions or more were classified as good knowledge.

Part two in the KAP questionnaire was a practice part containing three main subsections. The first question related to heme-iron intake, while the second related to usual consumption of citrus food. If the answer to the first question is "Yes", participants are required to answer two questions but will skip the two questions if they answered "No" to the first question. Finally, a subsection investigated the participants regarding consumption of tea and coffee; the answers in the first subsection were coded, so "Yes" means " +2 " and No means " 2 ". On the other hand, the answers to the first question in the second subsection were coded to be " 0 " for "Yes" answers, while "- 2 " was given for "No" answers. It is worth mentioning that the second question in this subsection was coded differentially, as "+1" was given to "Yes" answers and "0" was given to the other ones. The answers to the third question were coded as follows; before, during and after the meal were given " 0 ". The first answer for the first question in the third subsection was coded as " 0 " for "Yes" answers. While the other answers were given "+2". The answers to the last question were coded as follows; $\geq 2$ hours after or before a meal were given " +1 ", while the rest were given “-1".

The third part of the KAP questionnaire aimed to identify the attitude of the participants towards an ideal or desired 
nutrition practice and contained six questions. The first question was excluded to avoid bias as it is a descriptive question which, by default, will be answered correctly by the participants as they had been informed of the results of blood analysis concerning the ID or IDA. The answers to the remaining five questions in the section were coded as " 0 ", "1", and "2" to indicate first, second, and third response, respectively. The weights for the responses were calculated and changed into percentage with $50 \%$ or more indicating a positive attitude and less than $50 \%$ indicating a negative attitude.

\subsection{Statistical Analysis}

KAP questionnaire scores were measured twice, before, and after the nutrition education intervention. SPSS version 21 was used to analyse the data. The total scores of knowledge, attitude, and practice pre- and post- the nutrition educational intervention were tested for normality of distribution using the Shapiro-Wilk test. The data were not a normal distribution data; as such median was calculated as a measure of central tendency, and interquartile range as a measure of variance. To compare the scores pre- and post-intervention, the Wilcoxon signed ranks test was used. A $p$-value less than 0.05 was regarded as statistically significant.

\section{Results}

The age of the female adolescents ranged from 15.0 to 18.3 years, and the median age was 16.2 years. Table 1 represents the sociodemographic and anthropometric characteristics of female adolescents. Participants were divided into three age groups with 37 female adolescents aged 15-16 years old, 29 females aged 16-17 years old, and 23 females aged 17-19, respectively.

Table 1. Sociodemographic and anthropometric characteristics of the sample

\begin{tabular}{lll}
\hline & Categories & $\mathrm{n}(\%)$ \\
\hline Age (years) & $15-16$ & $37(41.6)$ \\
& $16-17$ & $29(32.6)$ \\
& $17-19$ & $23(25.8)$ \\
\hline Grade & 10 & $34(38.2)$ \\
& 11 & $22(24.7)$ \\
& 12 & $33(37.1)$ \\
Region & North Gaza & $14(15.7)$ \\
& Gaza & $25(28.1)$ \\
& Middle Area & $24(27.0)$ \\
Khan Younis & $15(16.9)$ \\
Rafah & $11(12.4)$ \\
\hline
\end{tabular}

Table 2 represents the results of haemoglobin and ferritin parameters between two groups. The means of haemoglobin and ferritin in the control group and nutrition education intervention group were (11.52 and 11.45 $\mathrm{g} / \mathrm{dl})$ and $(9.19$ and $9.92 \mu \mathrm{g} / \mathrm{l})$, respectively.

Table 2. Blood parameters of intervention and control groups at baseline $(n=89)$

\begin{tabular}{lllll}
\hline & Mean \pm SD & Median(IQR) & \multicolumn{2}{l}{$95 \%$ CI for Mean } \\
\cline { 4 - 4 } & & & Lower & Upper \\
\hline Control group $(\mathrm{n}=45)$ & & & 11.23 & 11.81 \\
$\mathrm{Hb}(\mathrm{g} / \mathrm{dl})$ & $11.52 \pm 0.96$ & $11.5(1.3)$ & 8.30 & 10.08 \\
Ferritin $(\mu \mathrm{g} / \mathrm{l})$ & $9.19 \pm 2.92$ & $8.60(4.0)$ & & \\
\hline Intervention group $(\mathrm{n}=42)$ & & & 11.09 & 11.81 \\
$\mathrm{Hb}(\mathrm{g} / \mathrm{dl})$ & $11.45 \pm 1.18$ & $11.45(1.8)$ & 8.96 & 10.87 \\
Ferritin $(\mu \mathrm{g} / \mathrm{l})$ & $9.92 \pm 3.16$ & $10.50(4.5)$ & \\
\hline
\end{tabular}


Table 3 shows the evaluation of KAP among participants before and after the nutrition education intervention and stipulates that $77.8 \%$ of adolescents in the control group and $77.3 \%$ of adolescents in the nutrition education groups had a low level of knowledge. In addition, the results of not-desired practice and negative attitude between the control and nutrition education groups were 64.4 and 63.6 , and 40.0 and $45.5 \%$, respectively. On the other hand, the same table indicates that $80.0 \%$ of the control group and $9.1 \%$ of the intervention group had low knowledge, while the remaining had good knowledge. In addition, results of practice and attitude between the control and intervention groups were 53.3 and $29.5 \%$, and 40.0 and $29.5 \%$, respectively.

Table 3. Pre-and post KAP results between control and intervention groups

\begin{tabular}{|c|c|c|c|}
\hline & & Control $n=45$ & \multirow{2}{*}{$\begin{array}{l}\text { Intervention } \mathrm{n}=44 \\
\mathrm{~N}(\%)\end{array}$} \\
\hline & & $\mathrm{N}(\%)$ & \\
\hline \multicolumn{4}{|l|}{ Pre-intervention } \\
\hline \multirow[t]{2}{*}{ Knowledge } & Good & $10(22.2)$ & $10(22.7)$ \\
\hline & Low & $35(77.8)$ & $34(77.3)$ \\
\hline \multirow[t]{2}{*}{ Attitude } & Positive & $27(60.0)$ & $24(54.5)$ \\
\hline & Negative & $18(40.0)$ & $20(45.5)$ \\
\hline \multirow[t]{2}{*}{ Practice } & Desired & $16(35.6)$ & $16(36.4)$ \\
\hline & Not-desired & $29(64.4)$ & $28(63.6)$ \\
\hline \multicolumn{4}{|l|}{ Post-intervention } \\
\hline \multirow[t]{2}{*}{ Knowledge } & Good & $9(20.0)$ & $40(90.9)$ \\
\hline & Low & $36(80.0)$ & $4(9.10)$ \\
\hline \multirow[t]{2}{*}{ Attitude } & Positive & $27(60.0)$ & $31(70.5)$ \\
\hline & Negative & $18(40.0)$ & $13(29.5)$ \\
\hline \multirow[t]{2}{*}{ Practice } & Desired & $21(46.7)$ & $31(70.5)$ \\
\hline & Not-desired & $24(53.3)$ & $13(29.5)$ \\
\hline
\end{tabular}

Table 4 represents the change of knowledge after six months in control and intervention groups (pre-and post-intervention). The number of female adolescents at the end-point was 45 and 44 for the control and intervention groups, respectively. There was no significant increase in the knowledge score in the control group. However, a significant increase was noted in the intervention group. The score at baseline (median) of the control group showed a small increase compared to the end-line (median) score of the same group ( $M d n=25.00$, and 37.50$)$ and this increase was not statistically significant. On the other hand, there was a significant change of the median from baseline to end-line intervention for the intervention group who received nutritional education session for three months ( $M d n=31.25$ vs. $75.00, \mathrm{Z}=-5.426, p<0.001)$.

The changes in attitude after six months in the control and intervention groups. The median of attitude test showed little change in the control group between pre-and post-attitude tests $(M d n=25.00 \mathrm{vs} .37 .50, Z=-.521, p=0.602)$ as shown as in Table 4. On the other hand, the intervention group who received nutrition education session showed that the median of attitude scores was significantly changed ( $M d n=31.25$ vs. $75.00, \mathrm{Z}=-3.825, p<0.001)$. On the other hand, the same table represents the changes in practice scores after six months in the control and intervention groups. The number of participants who were analysed after six months were 45 and 44 for the control and intervention groups, respectively. The median of practice scores showed little change in the control group between pre- and post-practice tests ( $M d n=53.33$ vs. $60.00, Z=-1.657, p=0.098)$. On the other hand, the median of practice scores changed significantly from baseline to end-line intervention for the group that received nutrition education sessions ( $M d n=60.00$ vs. $73.33, \mathrm{Z}=-3.170, p=0.002)$. 
Table 4. KAP Changes Test pre-and post-intervention among 2 groups

\begin{tabular}{|c|c|c|c|c|}
\hline \multirow[t]{2}{*}{ Groups } & \multicolumn{2}{|c|}{ Median (IQR) } & \multirow[t]{2}{*}{ Test Value } & \multirow[t]{2}{*}{$p$} \\
\hline & Knowledge Pre-Test & Knowledge Post-Test & & \\
\hline Control & $25.00(25.00)$ & $37.50(12.50)$ & $Z=-1.709$ & 0.25 \\
\hline \multirow[t]{2}{*}{ Intervention } & $31.25(25.0)$ & $75.00(25.00)$ & $Z=-5.426$ & $<0.001 *$ \\
\hline & Attitude Pre-Test & Attitude Post-Test & & \\
\hline Control & $25.00(25.00)$ & $37.50(12.50)$ & $Z=-.521$ & 0.60 \\
\hline \multirow[t]{2}{*}{ Intervention } & $31.25(25.0)$ & $75.00(25.00)$ & $Z=-3.825$ & $<0.001 *$ \\
\hline & Practice Pre-Test & Practice Post-Test & & \\
\hline Control & $53.33(33.33)$ & $60.00(26.66)$ & $Z=-1.657$ & 0.09 \\
\hline Intervention & $60.00(26.66)$ & $73.33(20.00)$ & $Z=-3.170$ & $0.002 *$ \\
\hline
\end{tabular}

* Difference is significant at the 0.05 level (2-tailed).

\section{Discussion}

The intervention group in this study showed a significant improvement in KAP regarding iron deficiency anaemia. Other studies have reported similar findings regarding other aspects regardless of IDA (Harrabi et al., 2010; Powers, Struempler, Guarino, \& Parmer, 2005; Puri et al., 2008; Rani et al., 2013; Saibaba, Mohan Ram, Ramana Rao, \& Uma Devi, 2002). Previous studies found that gaining knowledge is one of the first stages of a move towards a change of behaviour. Nutrition knowledge is therefore an essential basis for good dietary habits (Alderman, 2007; Spendlove et al., 2012). Individuals who had better nutrition knowledge had a more positive attitude towards eating healthier foods (Garcia-Lascurain, Kicklighter, Jonnalagadda, Boudolf, \& Duchon, 2006; Heaney, O'Connor, Michael, Gifford, \& Naughton, 2011). Conversely, poor knowledge is one of the risk factors to develop malnutrition (Ryoo, 2011).

The nutrition education intervention for nine sessions ( $1 \frac{1}{2}$ hours weekly) was found to be effective in significantly improving KAP. This finding is consistent with a previous study conducted among adolescents students in India which concluded that ten weeks of nutrition education programme (one hour weekly) led to significant improvements in nutrition KAP, as well as a decrease in consumption of junk foods (Rani et al., 2013). Moreover, the nutrition education material such as lectures, brochures, and videos in the current study may have contributed to the improvement in knowledge scores among the intervention group. Similar findings were reported among female adolescents and young students (Ruzita, Wan Azdie, \& Ismail, 2007; Yusoff, Wan Daud, \& Ahmad, 2012).

The findings of this study demonstrated the positive effect of nutrition education KAP among female adolescents, and the findings are in agreement with other studies (Gupta \& Kochar, 2009; Kaur \& Singh, 2001; Moore, Pawloski, Rodriguez, Lumbi, \& Ailinger, 2009; Yusoff et al., 2012). Another study in India reported that the improvements in KAP were 30.0\%, 22.0\%, and 6.8\%, respectively (Rani et al., 2013). Another study conducted in the same country concluded that the improvements were $4.5 \%, 4.6 \%$, and $31.1 \%$, respectively (Singla, Sachdeva, $\&$ Kochhar, 2012). Furthermore, our findings were consistent with a recent study conducted among female adolescents in India that reported the mean nutrition knowledge score as 25.9\% (Webb \& Beckford, 2014).

This study found that the median score of knowledge among female adolescents aged 15-19 years improved from median 31.25 vs. 75.0 , and that this improvement was statistically significant $(p<0.01)$ among the intervention group, but non-significant among the control group (median $=25.0$ vs. 37.0 ). This result was consistent with a study conducted in India among female adolescents aged 16-18 years, which reported that the mean scores for nutrition knowledge improved significantly from $25.00-36.24 \%$, and non-significantly (21.80 to $22.13 \%)$ in the intervention and control group, respectively (Singla et al., 2012). On the other hand, the mean score of attitude in the current study before the intervention was $54.5 \%$ among intervention group, and this percentage was lower than the percentage measured in 2014 in India among the same age group (75.1\%). However, this difference may be due to the content of the KAP questionnaire, different context and location. The current KAP is related to IDA, while the other was related to healthy diet.

Nutrition education evaluations established that an average of 10-15 hours of education was required to effect a significant increase in knowledge (Mohd Shariff et al., 2008), although the current study revealed that participating in 13 hours of nutrition education could cause significant improvements in KAP, as also proved in another study 
(Mohd Shariff et al., 2008). Nutrition education caused a significant improvement in KAP regarding iron deficiency anaemia in the intervention group. The findings are consistent with a study done in Malaysia (Mohd Shariff et al., 2008).

\section{Strength and Limitations}

This study targeted a specific group of female adolescents who were at high risk of IDA. The KAP questionnaire which was used was a recent questionnaire adopted from FAO (Marías \& Glasauer, 2014). The nutrition educational intervention was relatively simple and short-term (1.5 hours for 9 weeks), making it realistic to implement in the Palestinian setting. This is in contrast to nutrition intervention studies (Powers et al., 2005; Sallis et al., 2003; Shi-Chang et al., 2004) which have tested complex nutrition programmes with large samples which would be difficult to implement in Palestine (Rani et al., 2013; Shariff Mohd Zalilah et al., 2008). On the other hand, this study was limited to the Gaza Strip area only and therefore does not necessarily represent Palestine.

\section{Conclusions}

Low scores of KAP regarding iron deficiency anaemia were noted among iron-deficient female adolescents in the Gaza Strip, Palestine. Iron deficient female adolescents in the Gaza Strip were found to have insufficient nutrition knowledge, which could contribute to their haemoglobin and ferritin levels. However, for normal ferritin and haemoglobin levels, there is a need for good knowledge, positive attitude, and good practice. Nutrition education intervention was found to improve KAP significantly. More nutritional interventional research is needed on different malnutrition sectors.

\section{Acknowledgements}

The authors would like to thanks all the female adolescents of this research for their cooperation and willingness to complete the questionnaire and blood collection.

\section{Competing Interests Statement}

The authors declare that there are no conflicts of interest.

\section{Ethics and Consent}

Ethical approval was obtained from the Ethical Committee at UKM, Malaysia (Ref: UKM1.5.3.5/244/NN025-2015) and the Helsinki Committee of the Palestinian Ministry of Health (Ref: PHRC/HC/3/14-2015). The female adolescents signed a consent form to enrol in this study before conducting it.

\section{Authors' Contributions}

All authors designed the work towards submission of this article. M. J. analysed the data. All authors contributed to interpretation and writing of the manuscript and approved the final version for submission.

\section{References}

Alderman, H. (2007). Improving nutrition through community growth promotion: longitudinal study of the nutrition and early child development program in Uganda. World development, 35(8), 1376-1389. http://dx.doi.org/10.1016/j.worlddev.2007.04.003

Aung, P. P., Foung, C. S., Azman, K. B., Ain, N., \& Zulkifeli, B. (2012). Knowledge, attitude and practice of healthy eating among the 1st and 2nd year students of Universiti Malaysia Sarawak (UNIMAS). Paper presented at the Int. Conf. Nutr. Food Sci. IPCBEE.

Black, R. E., Victora, C. G., Walker, S. P., Bhutta, Z. A., Christian, P., De Onis, M., . . Martorell, R. (2013). Maternal and child undernutrition and overweight in low-income and middle-income countries. The Lancet, 382(9890), 427-451. http://dx.doi.org/10.1016/S0140-6736(13)60937-X

Divakaran, B., Muttapillymyalil, J., Sreedharan, J., \& Shalini, K. (2010). Lifestyle risk factors of noncommunicable diseases: awareness among school children. Indian journal of cancer, 47(5), 9-13. http://dx.doi.org/10.4103/0019-509X.63864

Elhassan, M. R., Gamal, H. E., \& Mohammed, G. S. (2013). Nutrition knowledge attitude and practices among students of Ahfad University for women. Indian Journal of Scientific Research, 4(1), 25-34

Garcia-Lascurain, M. C., Kicklighter, J. R., Jonnalagadda, S. S., Boudolf, E. A., \& Duchon, D. (2006). Effect of a Nutrition Education Program on NutritionRelated Knowledge of English-as-Second-Language Elementary School Students: A Pilot Study. Journal of Immigrant and Minority Health, 8(1), 57-65. http://dx.doi.org/10.1007/s10903-006-6342-9 
Gupta, N., \& Kochar, K. (2009). Role of nutrition education in improving the nutritional awareness among adolescent girls. The Internet Journal of Nutrition and Wellness, 7(1), 1-6

Harrabi, I., Maatoug, J., Gaha, M., Kebaili, R., Gaha, R., \& Ghannem, H. (2010). School-based intervention to promote healthy lifestyles in Sousse, Tunisia. Indian Journal of community medicine, 35(1), 94-99. http://dx.doi.org/10.4103/0970-0218.62581

Heaney, S., O’Connor, H., Michael, S., Gifford, J., \& Naughton, G. (2011). Nutrition knowledge in athletes: A systematic review. Int J Sport Nutr Exerc Metab, 21(3), 248-261. http://dx.doi.org/10.1123/ijsnem.21.3.248

Hiew, C., Chin, Y., Chan, Y., \& Mohd, N. M. (2015). Development and Validation of Knowledge, Attitude and Practice on Healthy Lifestyle Questionnaire (KAP-HLQ) for Malaysian Adolescents. Journal of Nutrition and Health Sciences, 2(4), 1-11. http://dx.doi.org/10.15744/2393-9060.2.407

Kaur, M., \& Singh, K. (2001). Effect of health education on knowledge, attitude and practices about anaemia among rural women in Chandigarh. Indian Journal of community medicine, 26(3), 128-132

Marías, Y. F., \& Glasauer, P. (2014). Guidelines for assessing nutrition-related knowledge, attitudes and practices Y. F. Macias \& P. Glasauer (Eds.),

Miller, L. A., \& Lovler, R. L. (2015). Foundations of psychological testing: A practical approach (5th ed.). USA: SAGE Publications.

Mohd Shariff, Z., Abu Samah, B., Paim, L., Ismail, M., Kasim, M. S., Othman, N., . . . Hussein, M. (2008). Nutrition education intervention improves nutrition knowledge, attitude and practices of primary school children: a pilot study. International Electronic Journal of Health Education, 11(1), 119-132

Moore, J. B., Pawloski, L., Rodriguez, C., Lumbi, L., \& Ailinger, R. (2009). The effect of a nutrition education program on the nutritional knowledge, hemoglobin levels, and nutritional status of Nicaraguan adolescent girls. Public Health Nursing, 26(2), 144-152. http://dx.doi.org/10.1111/j.1525-1446.2009.00765.x

Nguyen, M. F. R., Orillo, A. T. O., Hagos, R. A. F., Javier, C. A. Z., Alcantara, R. M., \& Talavera, M. T. M. (2013). Association of Adolescents' Knowledge, Attitude, and Practices (KAP) on Nutrition Labels and their Nutritional Status. Journal of Human Ecology, 1(1), 963-964

Øvrebø, E. M. (2014). Knowledge and attitudes of adolescents regarding home economics in Tromsø, Norway. International Journal of Consumer Studies, 38(1), 2-11. http://dx.doi.org/10.1111/ijcs.12043

Patimah, S., Royani, I., Mursaha, A., \& Thaha, A. R. (2016). Knowledge, attitude and practice of balanced diet and correlation with hypochromic microcytic anemia among adolescent school girls in maros district, South Sulawesi, Indonesia. Biomedical Research, 27(1), 165-171

Powers, A. R., Struempler, B. J., Guarino, A., \& Parmer, S. M. (2005). Effects of a nutrition education program on the dietary behavior and nutrition knowledge of second - grade and third - grade students. Journal of school health, 75(4), 129-133. http://dx.doi.org/10.1111/j.1746-1561.2005.tb06657.x

Priyanka, P., \& Asfia, H. (2015). A Study on Anemia Related Knowledge Among Adolescent Girls. International Journal of Nutrition and Food Sciences, 4(3), 273-276. http://dx.doi.org/ 10.11648/j.ijnfs.20150403.14

Puri, S., Bhatia, H., Swami, S., Rai, C., \& Mangat, C. (2008). Impact of a diet and nutrition related education package on the awareness and practices of school children of Chandigarh. The Internet J of Epidemiology, $6(1), 1-7$.

Rani, M. A., Shriraam, V., Zachariah, R., Harries, A. D., Satyanarayana, S., Tetali, S., . . Sathiyasekaran, B. (2013). Does a nutrition education programme change the knowledge and practice of healthy diets among high school adolescents in Chennai, India? Health Education Journal, 72(6), 733-741. https://doi.org/10.1177/0017896912461093

Reynolds, C. R., \& Livingston, R. B. (2013). Mastering modern psychological testing: Theory \& methods (First Edition ed.). New York, NY: Pearson.

Roszanadia, R., \& Norazmir, M. (2011). Knowledge, Attitude and Practice on Healthy Eating ainong Special Needs Boarding School Students. International Journal of Dairy Science, 6(5), 1-9. http://dx.doi.org/ 10.3923/ijds.2011.278.286

Ruzita, A., Wan Azdie, M., \& Ismail, M. (2007). The effectiveness of nutrition education programme for primary school children. Mal J nutr, 13(1), 45-54

Ryoo, E. (2011). Adolescent nutrition: what do pediatricians do? Korean journal of pediatrics, 54(7), $287-291$. 
https://doi.org/10.3345/kjp.2011.54.7.287

Saibaba, A., Mohan Ram, M., Ramana Rao, G., \& Uma Devi, S. T. (2002). Nutritional status of adolescent girls of urban slums and the impact of IEC on their nutritional knowledge and practices. Indian J Community Med, 27(4), 151-156

Sallis, J. F., McKenzie, T. L., Conway, T. L., Elder, J. P., Prochaska, J. J., Brown, M., . . Alcaraz, J. E. (2003). Environmental interventions for eating and physical activity: a randomized controlled trial in middle schools. American journal of preventive medicine, 24(3), 209-217. http://dx.doi.org/10.1016/S0749-3797(02)00646-3

Shariff Mohd Zalilah, Abu Samah, B., Paim, L., Ismail, M., Kasim, M. S., Othman, N., . . Hussein, M. (2008). Nutrition education intervention improves nutrition knowledge, attitude and practices of primary school children: a pilot study. International Electronic Journal of Health Education, 11(1), 119-132

Shi-Chang, X., Xin-Wei, Z., Shui-Yang, X., Shu-Ming, T., Sen-Hai, Y., Aldinger, C., \& Glasauer, P. (2004). Creating health-promoting schools in China with a focus on nutrition. Health Promotion International, 19(4), 409-418. http://dx.doi.org/10.1093/heapro/dah402

Sichert-Hellert, W., Beghin, L., De Henauw, S., Grammatikaki, E., Hallström, L., Manios, Y., . . Piccinelli, R. (2011). Nutritional knowledge in European adolescents: results from the HELENA (Healthy Lifestyle in Europe by Nutrition in Adolescence) study. Public health nutrition, 14(12), 2083-2091. https://doi.org/10.1017/S1368980011001352

Singla, P., Sachdeva, R., \& Kochhar, A. (2012). Impact of Nutrition Counseling on Consumption Pattern of Junk Foods and Knowledge, Attitudes and Practices among Adolescent Girls of Working Mothers. Journal of Human Ecology-New Delhi, 39(3), 221.

Spendlove, J. K., Heaney, S. E., Gifford, J. A., Prvan, T., Denyer, G. S., \& O'Connor, H. T. (2012). Evaluation of general nutrition knowledge in elite Australian athletes. British Journal of Nutrition, 107(12), 1871-1880. https://doi.org/10.1017/S0007114511005125

Waisbord, S. (2014). Where do we go next? Behavioral and social change for child survival. Journal of health communication, 19(1), 216-222. http://dx.doi.org/10.1080/10810730.2014.933288

Webb, M. C., \& Beckford, S. E. (2014). Nutritional knowledge and attitudes of adolescent Swimmers in Trinidad and Tobago. Journal of nutrition and metabolism, 2014(ID: 506434), 1-7. http://dx.doi.org/10.1155/2014/506434

WHO. (2008). Advocacy, communication and social mobilization for TB control: A guide to developing knowledge, attitude and practice surveys.

WHO. (2010). Life skills education in schools, programme on mental health.

Yusoff, H., Wan Daud, W., \& Ahmad, Z. (2012). Nutrition education and knowledge, attitude and hemoglobin status of Malaysian adolescents. Southeast Asian Journal of Tropical Medicineand Public Health, 43(1), 192-200.

\section{Copyrights}

Copyright for this article is retained by the author(s), with first publication rights granted to the journal.

This is an open-access article distributed under the terms and conditions of the Creative Commons Attribution license (http://creativecommons.org/licenses/by/4.0/). 